Original Research Paper

\title{
Assessment of the Toxic Effects of Chitosan-Coated Magnetite Nanoparticles on Drosophila melanogaster
}

\author{
${ }^{1}$ Doris Vela, ${ }^{1,5}$ Jonathan Rondal, ${ }^{3}$ Sofía Cárdenas, ${ }^{4}$ José Gutiérrez-Coronado, \\ ${ }^{3}$ Eliza Jara, ${ }^{2}$ Alexis Debut and ${ }^{3}$ Fernanda Pilaquinga \\ ${ }^{1}$ Facultad de Ciencias Exactas y Naturales, Laboratorio de Genética Evolutiva, \\ Pontificia Universidad Católica del Ecuador, Quito, Ecuador \\ ${ }^{2}$ Centro de Nanociencias y Nanotecnología, Universidad de las Fuerzas Armadas ESPE, Sangolquí, Ecuador \\ ${ }^{3}$ Facultad de Ciencias Exactas y Naturales, Laboratorio de Nanotecnología, \\ Pontificia Universidad Católica del Ecuador, Quito, Ecuador \\ ${ }^{4}$ Universidad Autónoma de Madrid, Madrid, Spain \\ ${ }_{5}^{5}$ Departamento de Ciencias de la Vida y la Agricultura, Universidad de las Fuerzas Armadas ESPE, Sangolquí, Ecuador
}

\author{
Article history \\ Received: 16-07-2020 \\ Revised: 14-09-2020 \\ Accepted: 25-09-2020 \\ Corresponding Author: \\ Doris Vela \\ Facultad de Ciencias Exactas y \\ Naturales, Laboratorio de \\ Genética Evolutiva, Pontificia \\ Universidad Católica del \\ Ecuador, Quito, Ecuador \\ Email: dvela508@puce.edu.ec
}

\begin{abstract}
Nanoparticles are a cause for concern because of their potential toxic effects on human health and the environment. The aim of this study was to assess the toxic effect of chitosan-coated magnetite nanoparticles $(11.00 \pm 4.7 \mathrm{~nm})$ on Drosophila melanogaster through the observation of hemolymph composition, DNA damage, larval survival and lifespan of flies. Chitosan-coated magnetite nanoparticles were synthesized by coprecipitation method. Drosophila larvaes and adults were exposed to 500 and $1000 \mathrm{ppm}$ nanoparticles solution. After exposure, each type of larval hemocytes was recognized. Comet assay was performed to detect the DNA damage in the hemocytes. Also, the larval survival and lifespan of exposed flies were observed. Our results showed the toxic effect of the chitosan-coated magnetite nanoparticles through the increment of hemocytes, the emergence of lamellocytes, the presence of apoptotic hemocytes and the DNA damage detected by comet assay. In addition, nanoparticles produce decreasing of larval survival and shortening of the mean and maximum lifespan. The toxic effect the chitosan-coated magnetite nanoparticles is directly associated with $1000 \mathrm{ppm}$. No DNA damage was observed at $500 \mathrm{ppm}$.
\end{abstract}

Keywords: Comet Assay, Chitosan, Magnetite Nanoparticles, Hemolymph, Lifespan

\section{Introduction}

Drosophila melanogaster has proved to be a suitable organism for testing the toxic effects of nanomaterials (Canesi et al., 2015; Galenza and Foley, 2019; Ong et al., 2015; Wilson-Sanders, 2011) for example by observing the migration and dynamics of hemolymph cell (Fauvarque and Williams, 2011), DNA damage in hemocytes (Carmona et al., 2015a; 2015b; Chifiriuc et al., 2016), survival of larvaes and changes in the lifespan (Chifiriuc et al., 2016; Massie et al., 1985).

In Drosophila, the cellular immune response is directly mediated by hemocytes changes in the density of hemolymph cell can be induced by foreign stimulus (Gillespie et al., 1997; Irving et al., 2005; Lackie, 1988). The Drosophila hemolymph includes three types of hemocytes: Plasmatocytes $(95 \%)$ have the capacity to remove foreign material by phagocytosis; crystal cells $(5 \%)$ are involved in melanin synthesis during pathogen encapsulation (Söderhäll and Cerenius, 1998); and lamellocytes, which are large, flattened cells whose differentiation is induced in response to patogens or the presence of foreign particles in the hemocoel (Carmona et al., 2015a; Cherry and Silverman, 2006; Irving et al., 2005; Lemaitre and Hoffmann, 2007). Also, the hemocytes are suitable cells to detect the DNA damage through the comet assay (Alaraby et al., 2015; Carmona et al., 2015b; Gajski et al., 2019). Lifespan of Drosophila could be critically influenced by the components of food, for example, the presence of iron in the diet produce accumulation of iron, shortening lifespan and senescence in the flies (Massie et al., 1985), 
while carotenoids, some amino acids and proteins prolong the lifespan due to their antioxidant action (Hoedjes et al., 2017; Zhang et al., 2014; Zhou et al., 2018).

Magnetic nanoparticles are of great interest in biomedicine because of their diverse applications, which include drug delivery vehicles, tissue engineering, hyperthermia treatment for tumors and as contrast agents in magnetic resonance imaging (Markides et al., 2012). From a chemical perspective, they are considered inert in biological media. Both in vitro and in vivo studies have revealed no obvious toxicity of magnetic nanoparticles, but potential toxicity has been observed in blood in organisms that have been exposed to magnetic nanoparticles (Elsabahy and Wooley, 2015; Sun et al., 2017).

Magnetite is a type of iron oxide $\left(\mathrm{Fe}_{3} \mathrm{O}_{4}\right)$ found in nature as cubic crystals (Iacovita et al., 2015). At the macroscopic scale, it behaves as a ferrimagnetic material, while at the nanometric scale, it is superparamagnetic (Iacovita et al., 2015). Magnetite has a highly reactive surface; thus, it can immobilize metals, enzymes and other molecules, giving it other functionalities, as they will provide different chemical groups to the surface without altering its magnetic properties (Ghazanfari et al., 2016). If no coating is present, magnetite nanoparticles $\left(\mathrm{Fe}_{3} \mathrm{O}_{4} \mathrm{NPs}\right)$ have a hydrophobic exterior, which facilitates the formation of agglomerates and, subsequently, bulky aggregates. NPs have a tendency toward aggregation, especially in biological fluids, due to the presence of salts and plasmatic proteins. These aggregates are incompatible with biomedical applications because they can obstruct blood capillaries (Hedayatnasab et al., 2018). A biocompatible cover layer may provide a physical barrier that prevents particle agglomeration.

Several researchers have demonstrated the toxicity of magnetite nanoparticles through in vitro and in vivo studies (Mojica Pisciotti et al., 2014; S Shukla et al., 2015). Zhang et al. (2016) evaluated the toxicity and biological behavior of magnetite nanoparticles in umbilical cord cells, showing that inflammation processes (but not apoptosis) occur within $24 \mathrm{~h}$ in concentrations up to $400 \mu \mathrm{g} \mathrm{mL} \mathrm{m}^{-1}$. On the other hand, (Ma et al., 2012) performed a toxicity test of magnetite nanoparticles in mice; the results showed tissue damage at concentrations above $5 \mathrm{mg} \mathrm{kg}^{-1}$.

Chitosan (Ch) is the most abundant natural polysaccharide after cellulose and hemicellulose. It is a nontoxic, biodegradable and biocompatible polysaccharide obtained from the deacetylation of chitin, which is found in crustacean exoskeletons. Chitosan has amino and hydroxyl reactive groups that enable it to form new compounds, leading to different applications such as protein and metal adsorption (Kumar et al., 2016; López et al., 2013; Shukla et al., 2015).
In this study, the aim was to observe the toxic effect Ch- $\mathrm{Fe}_{3} \mathrm{O}_{4} \mathrm{NPs}$ on Drosophila melanogaster larvae hemolymph after exposure. For this, third instar larvae were exposed to 500 and 1000 ppm (parts per million, equivalent to $\mathrm{mg} / \mathrm{L}$ ) of $\mathrm{Ch}-\mathrm{Fe}_{3} \mathrm{O}_{4} \mathrm{NPs}$ during $24 \mathrm{~h}$. The toxic effect was evaluated using hemolymph in terms of total number of hemocytes, apoptotic plasmatocytes, lamellocytes and DNA damage (comet assay). Additionally, the toxic effect of $\mathrm{Ch}-\mathrm{Fe}_{3} \mathrm{O}_{4} \mathrm{NPs}$ was observed through the mean and maximum lifespan and larval survival after exposure.

\section{Methods}

\section{Reagents}

Unless otherwise specified, all chemical substances employed in the experimental procedures were of high purity, i.e., analytical grade or superior, from Merck or $\mathrm{BDH}$ Chemicals. Chemical formulas of some reagents replace the following names: Sodium hydroxide $\mathrm{NaOH}$, hydrochloric acid $\mathrm{HCl}$, ferric chloride $\mathrm{FeCl}_{3}$, ferrous chloride $\mathrm{FeCl}_{2}$, ammonium hydroxide $\mathrm{NH}_{4} \mathrm{OH}$.

\section{Chitosan Extraction}

Wet shrimp exoskeletons (4 kg) were collected, kept refrigerated for two days, washed with water and ovendried at a temperature of $80^{\circ} \mathrm{C}$ for three days. They were then crushed in a grinder to obtain a powder; dry mass was approximately $12 \%$ of the initial weight. This powder was treated with $250 \mathrm{~mL}$ of xylene, stirred and heated for $24 \mathrm{~h}$ to remove pigments and later dried at $50^{\circ} \mathrm{C}$ in the oven for $24 \mathrm{~h}$. The obtained product was mixed with $250 \mathrm{~mL} \mathrm{NaOH} 6 \mathrm{~mol} \mathrm{~L}^{-1}$ at $65^{\circ} \mathrm{C}$, constantly stirred for $24 \mathrm{~h}$ and filtered with deionized water to remove all excess soda. Subsequently, it was decalcified with $250 \mathrm{~mL} \mathrm{HCl} 6 \mathrm{~mol} \mathrm{~L}^{-1}$ for $24 \mathrm{~h}$ with constant shaking. It was then washed, filtered and neutralized. The descaled precipitate (chitin) was deacetylated to obtain chitosan; the reaction was performed with $250 \mathrm{~mL}$ $\mathrm{NaOH} 17.5 \mathrm{~mol} \mathrm{~L}^{-1}$ for $24 \mathrm{~h}$ at $65^{\circ} \mathrm{C}$ and the mixture underwent constant stirring. Finally, it was filtered, neutralized and dried.

\section{$\mathrm{Ch}-\mathrm{Fe}_{3} \mathrm{O}_{4} \mathrm{NPs}$ Synthesis and Characterization}

$\mathrm{Ch}-\mathrm{Fe}_{3} \mathrm{O}_{4} \mathrm{NPs}$ were prepared as per the protocol suggested by (Gregorio-Jauregui et al., 2012) with slight modifications. All solutions were prepared in the lab the day before the experiments. Ch- $\mathrm{Fe}_{3} \mathrm{O}_{4} \mathrm{NPs}$ were synthetized by combining $50 \mathrm{~mL}$ of $\mathrm{FeCl}_{3} 6 \mathrm{H}_{2} \mathrm{O}$ $0.32 \mathrm{~mol} \mathrm{~L}^{-1}$ with $50 \mathrm{~mL}$ of $\mathrm{FeCl}_{2} 4 \mathrm{H}_{2} \mathrm{O} 0.2 \mathrm{~mol} \mathrm{~L}-1$ and $50 \mathrm{~mL}$ of chitosan $0.25 \%$ (w/v in acetic acid). The mix was heated at $50^{\circ} \mathrm{C}$ for 10 min with constant stirring; $20 \mathrm{~mL}$ of $\mathrm{NH}_{4} \mathrm{OH} 10 \mathrm{~mol} \mathrm{~L}^{-1}$ were added drop by drop (one drop every $2 \mathrm{~s}$ ) as a reducing agent. 
Immediately, the oxidative atmosphere became inert (helium atmosphere) for $20 \mathrm{~min}$. $\mathrm{Ch}-\mathrm{Fe}_{3} \mathrm{O}_{4} \mathrm{NPs}$ s were separated with the help of an $\mathrm{Nd}-\mathrm{Fe}-\mathrm{B}$ magnet (Supermagnete) and washed three times with $10 \mathrm{~mL}$ of deionized water and acetone in an ultrasonic bath (Branson 3510) for $10 \mathrm{~min}$. To activate the nanoparticles, they were washed three times with 10 $\mathrm{mL}$ of absolute ethanol and dispersed in pure water for $10 \mathrm{~min}$ in an ultrasonic bath at $40 \mathrm{kHz}$.

Transmission Electron Microscopy (TEM) micrographs were obtained using a FEI Tecnai G2 Spirit Twin at $80 \mathrm{kV}$ (Holland). Dynamic Light Scattering (DLS) was conducted with diluted solutions previously filtered with a $220 \mathrm{~nm}$ PVDF filter membrane (Whatman, China), using the HORIBA LB-550 analyzer. The elemental analysis was obtained by Energy Dispersive Xray Spectrometry (EDS), which was performed in an SEM chamber (Tescan Mira3) using a Bruker X-Flash 630 detector with a $123 \mathrm{eV}$ resolution at $\mathrm{Mn} \mathrm{K \alpha}$. A sample was fixed in a stub previously placed within two layers of conductive double-sided carbon tape and covered with 20 $\mathrm{nm}$ of a conductive gold layer (99.99\% purity) using a combined Quorum Q150R ES sputtering and evaporating system. The X-Ray Diffraction (XRD) measurement was carried out using an Empyrean diffractometer from PANalytical, operating in a $\theta-2 \theta$ configuration (BraggBrentano geometry) and equipped with a $\mathrm{Cu} \mathrm{X}$-ray tube (K $\alpha$ radiation $\lambda=1.54056 \AA$ ) operating at $40 \mathrm{kV}$ and 40 $\mathrm{mV}$. To obtain the size of the crystals (D), the Scherrer's formula Equation (1) was applied:

$$
D=k \lambda / \beta \cos \theta
$$

where, $\lambda$ is the wavelength of the $\mathrm{X}$-Ray sources, $k$ (= 0.89 ) is the Scherrer constant, $\beta$ is the experimental FullWidth at Half-Maximum (FWHM) of the respective diffraction peak (radians) and $\theta$ is the Bragg angles (Kroon, 2013). Fourier-Transform Infrared spectroscopy (FTIR) spectra were obtained using a Perkin Elmer Spectrm BX Spectrometer with Pike MIRacleTM ATR coupling (ZnSe crystal) ranging from 4000 to $520 \mathrm{~cm}^{-1}$, with $4 \mathrm{~cm}^{-1}$ resolution and 10 scans per sample.

\section{Exposure of D. melanogaster Larvae to Ch- $\mathrm{Fe}_{3} \mathrm{O}_{4} \mathrm{NPS}$}

Third instar D. melanogaster larvae (Oregon $\mathrm{R}+$ strain) were exposed to two treatments during $24 \mathrm{~h}$ : 500 and $1000 \mathrm{ppm}$ of $\mathrm{Ch}-\mathrm{Fe}_{3} \mathrm{O}_{4} \mathrm{NPs}$ and a control without nanoparticles (neither chitosan- nor magnetite-coated). $\mathrm{Ch}-\mathrm{Fe}_{3} \mathrm{O}_{4} \mathrm{NPs}$ were supplied through the culture medium, which was prepared by adding the corresponding number of nanoparticles to $1 \mathrm{~L}$ of culture medium and resuspended until homogenization following the procedure of (Ahamed et al., 2010). Fly maintenance and larvae exposures were conducted at $22^{\circ} \mathrm{C}$ and with a $12: 12$ light-dark cycle. The hemolymph of exposed larvae was extracted and analyzed to detect immune system cell activation through the total number of hemocytes, apoptotic plasmatocytes and lamellocytes, as well as DNA damage (comet assay).

\section{Hemocyte Count}

After exposure, $3 \mu \mathrm{L}$ of hemolymph was extracted from 30 larvae using the procedure of Palanker-Musselman (2013) and the hemocytes were stained with trypan blue 0.4\% (Santa Cruz Biotechnology). Each treatment was repeated three times. Based on the morphology and color, normal hemocytes (transparent cells), apoptotic plasmatocytes (blue cells) and lamellocytes (large, flat cells) were identified. The hemocytes were counted using a Neubauer chamber in a ZEISS Imager A2 microscope (40x/0.75); the number of hemocytes (normal hemocytes, apoptotic plasmatocytes and lamellocytes) in non-exposed larvae and larvae exposed to 500 and $1000 \mathrm{ppm}$ of $\mathrm{Ch}-\mathrm{Fe}_{3} \mathrm{O}_{4} \mathrm{NPs}$ was determined.

\section{Comet Assay}

The alkaline version of the comet assay was performed using hemocytes of larvae exposed to 500 and $1000 \mathrm{ppm}$ of $\mathrm{Ch}-\mathrm{Fe}_{3} \mathrm{O}_{4} \mathrm{NPs}$ and of the control group (non-exposed larvae), according to the protocol described in (Alaraby et al., 2015). The comets were visualized using an Olympus DP72 fluorescence microscope with a $100 \mathrm{x} / 0.17$ lens.

One hundred hemocyte comets were observed for each treatment. Image captures and comet tail length were measured using the ImageJ software version $1.50 \mathrm{e}$. The parameters used to estimate DNA damage were (a) percentage $(\%)$ of DNA in the comet tail and (b) tail length $(\mu \mathrm{m})$.

\section{Lifespan and Larval Survival}

To observe the nanoparticles' effect on lifespan, flies ( $\mathrm{n}=100$ per treatment) were isolated $24 \mathrm{~h}$ after emerging and placed in vials containing the culture medium for each treatment (500 and $1000 \mathrm{ppm}$ and the control without $\mathrm{Ch}-\mathrm{Fe}_{3} \mathrm{O}_{4} \mathrm{NPs}$ ). Flies were counted every day and placed in fresh culture medium (corresponding to each treatment) every 2-3 days. Mean lifespan was estimated as the number of days corresponding to the survival of $50 \%$ of the flies and maximum lifespan was estimated as the survival of $5 \%$. The survival curves were created with these data.

To determine larvae survival, third instar larvae $(\mathrm{n}=$ 100 per treatment) were exposed to each treatment (500 and $1000 \mathrm{ppm}$ in the culture medium and the control without $\mathrm{Ch}-\mathrm{Fe}_{3} \mathrm{O}_{4} \mathrm{NPs}$ ) and the emerged progeny were counted. Adults that did not emerge from pupae after 8 days were considered dead. Three repetitions were performed for each treatment and control to determine the survival percentage. 


\section{Statistical Analysis}

For the hemocytes count, statistical differences between treatments were analyzed through a one-way Analysis Of Variance (ANOVA) in SPSS 25.0 (Windows Version 25.0, NY, IBM Corp.). A Bonferroni post-hoc test was performed to compare differences between nanoparticle treatments versus the control test for each hemocyte type. A probability higher than 5\% (p-value $<0.05$ ) was considered statistically significant.

The comet assay, lifespan and larval survival results were analyzed with a one-way ANOVA test using SPSS 25.0. A probability higher than $5 \%$ ( $\mathrm{p}$-value $<0.05$ ) was considered statistically significant. A Bonferroni posthoc test was performed to compare the control versus the treatments exposed to $\mathrm{Ch}-\mathrm{Fe}_{3} \mathrm{O}_{4} \mathrm{NPs}$.

\section{Results}

\section{Characterization of $\mathrm{Ch}-\mathrm{Fe}_{3} \mathrm{O}_{4} \mathrm{NPS}$}

The TEM micrograph of Ch- $\mathrm{Fe}_{3} \mathrm{O}_{4} \mathrm{NPs}$ (Fig. 1A) and the shape frequency histogram (Fig. 1B) show the dispersed nanoparticles. The average size of the 155 TEM-measured nanoparticles was $11.0 \pm 4.7 \mathrm{~nm}$. This is consistent with the hydrodynamic diameters of the nanoparticles determined using DLS: $9.2 \pm 0.3 \mathrm{~nm}$ (Fig. 1C). Similar results obtained through TEM and DLS indicate that the chitosan coating is less than 1 nanometer (Ramesh et al., 2016).

Field Emission Gun Scanning Electron Microscope (FEG-SEM) micrograph furthermore inserted EDS spectrum are shown in Fig. 1D. The irregular surface of Ch$\mathrm{Fe}_{3} \mathrm{O}_{4} \mathrm{NPs}$ and the chemical composition which consists of $\mathrm{Fe}, \mathrm{C}, \mathrm{N}, \mathrm{O}$ and $\mathrm{Cl}$, are observed. Fe corresponds to the nanoparticles. Elements such as $\mathrm{C}, \mathrm{N}, \mathrm{O}$ are in chitosan and $\mathrm{Cl}$ comes from precursors of inorganic salts. To avoid biased determinations of the chemical composition of the samples due to their inhomogeneity, the spectra are obtained from a 25-point grid.

The $\mathrm{Ch}-\mathrm{Fe}_{3} \mathrm{O}_{4} \mathrm{NPs}$ crystalline nature was confirmed from the XRD analysis (Fig. 1E). The Bragg peaks at $36.06^{\circ}$ coincide with the cubic phase of $\mathrm{Fe}_{3} \mathrm{O}_{4}$ (ICSD: 96012). The lattice parameter and highest intensity plane (113) are well matched and consistent with other reported patterns (Gregorio-Jauregui et al., 2012). Additional peaks are observed around $15^{\circ}$ and $20^{\circ}$. To our knowledge, they correspond to chitosan extract impurities and their combination with the chemical compounds. Hematite or metal hydroxides were not identified, which confirms the complete formation of
$\mathrm{Fe}_{3} \mathrm{O}_{4}$. The Debye Scherrer equation at the highest reflection peak $\left(\mathrm{FWHM}=0.168^{\circ}\right)$ gives an approximate size of $50 \mathrm{~nm}$ for the $\mathrm{Fe}_{3} \mathrm{O}_{4} \mathrm{NPs}$. This calculated value is higher than the TEM and DLS values, which is likely due to the agglomeration of the organic extract.

FTIR spectra results demonstrated successful coating of magnetic nanoparticles with chitosan. Figure $1 \mathrm{~F}$ shows that the FTIR spectrum of the obtained $\mathrm{Ch}-\mathrm{Fe}_{3} \mathrm{O}_{4} \mathrm{NPs}$ displays a similar pattern to that of $\mathrm{Fe}_{3} \mathrm{O}_{4} \mathrm{NPs}$ and chitosan. In accordance with previous literature (Brugnerotto et al., 2001; Hedayatnasab et al., 2018; Ramesh et al., 2016), the characteristic absorption bands for pure chitosan appear at 3400 (O-H and $\mathrm{N}-\mathrm{H}$ stretching vibrations), 2800 (C-H stretching vibrations), 1600 ( N-H bending vibrations), ca. 1400 (C-N stretching vibrations) and $1000 \mathrm{~cm}^{-1}$ (CO-C stretching vibrations). The bands at 1600 and 1400 $\mathrm{cm}^{-1}$ appear broad due to the association of the amine group with NPs. In contrast to chitosan, the $\mathrm{Ch}$ $\mathrm{Fe}_{3} \mathrm{O}_{4} \mathrm{NPs}$ spectrum shows weak absorption bands around $1000-1100 \mathrm{~cm}^{-1}$ probably owing to structure stiffening by hydrogen bonds between $\mathrm{H}-\mathrm{N}$ ) $\mathrm{Ch}$...OH)NPs. One additional sharp band (NPs-peak) at 560 $\mathrm{cm}^{-1}$ also appears, which corresponds to $\mathrm{Fe}-\mathrm{O}$ stretching vibrations in magnetite (Brugnerotto et al., 2001).

\section{Hemocyte Count}

The changes in the total number of hemocytes and the presence of apoptotic or specialized cells were examined in the larval hemolymphs exposed to $\mathrm{Ch}$ $\mathrm{Fe}_{3} \mathrm{O}_{4} \mathrm{NPs}$. Apoptotic hemocytes were identified by the blue coloration after trypan blue passed through the cell membrane. Lamellocytes were observed as large and irregular cells (Fig. 2).

The total number of hemocytes increased in larvae exposed to $1000 \mathrm{ppm}$ (mean: 411.33) but decreased in larvae exposed to $500 \mathrm{ppm}$ (mean: 201.67) compared with the control group (mean: 235.67). The larvae exposed to $1000 \mathrm{ppm}$ also showed an increase in the number of apoptotic plasmatocytes (mean: 54.33) compared with the 500 ppm group (mean: 8.6) and control group (mean: 0.33 ). Lamellocytes were not present in the control larvae, but this type of cell was observed in the larvae exposed to 500 ppm (mean: 1.3) and 1000 ppm (mean: 13.3).

Statistical analysis for all counted cells (total number of hemocytes, apoptotic plasmatocytes and lamellocytes) showed little difference $(p \geq 0.05)$ between the larvae exposed to $500 \mathrm{ppm}$ and the control group but showed significant difference between the 1000 ppm treatment and the control group (Table 1).

Table 1: Hemocytes counts per treatment

\begin{tabular}{llll}
\hline Treatment & Total hemocytes & Apoptotic plasmatocytes & Lamellocytes \\
\hline Control & 707 & 1 & 0 \\
$500 \mathrm{ppm}$ & 605 & 26 & 4 \\
$1000 \mathrm{ppm}$ & $1234^{*}$ & $163 *$ & $40^{*}$ \\
\hline
\end{tabular}

\footnotetext{
*Statistical significant $\mathrm{p}<0.05$
} 

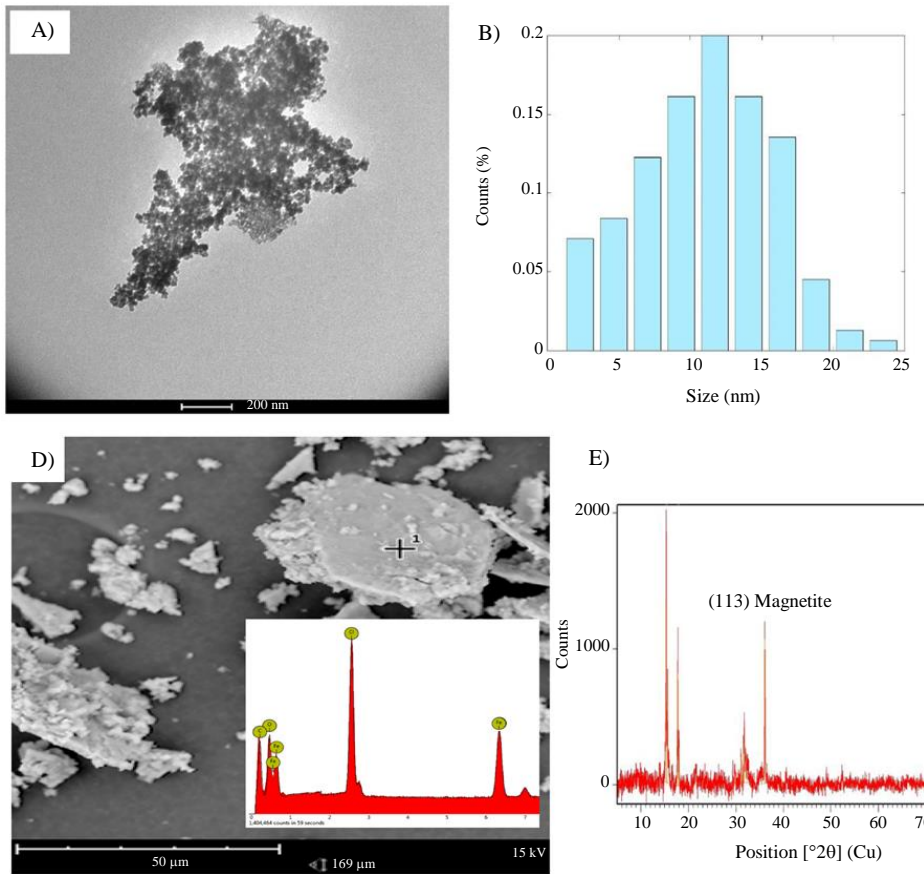

E)

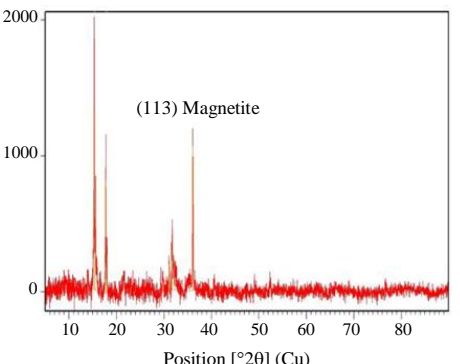

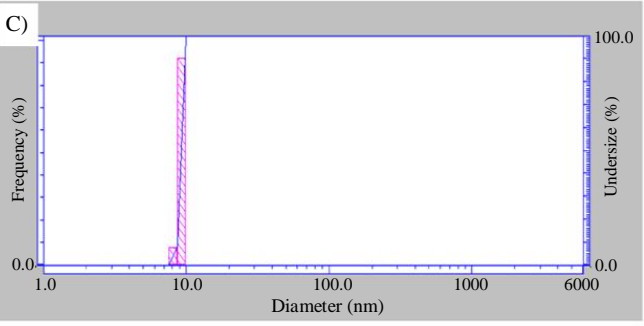

F)

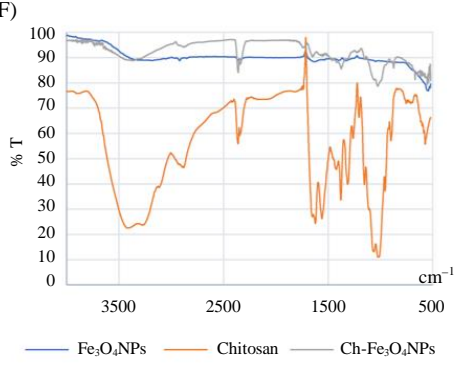

Fig. 1: Characterization of $\mathrm{Ch}-\mathrm{Fe}_{3} \mathrm{O}_{4} \mathrm{NPs}$ : TEM micrograph $\mathrm{Bar}=200 \mathrm{~nm}(\mathrm{~A})$, nanoparticle frequency histogram size (B), DLS

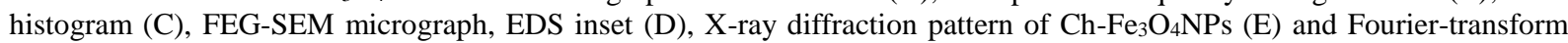
infrared spectroscopy spectra of $\mathrm{Fe}_{3} \mathrm{O}_{4} \mathrm{NPs}$, chitosan and $\mathrm{Ch}-\mathrm{Fe}_{3} \mathrm{O}_{4} \mathrm{NPs}(\mathrm{F})$

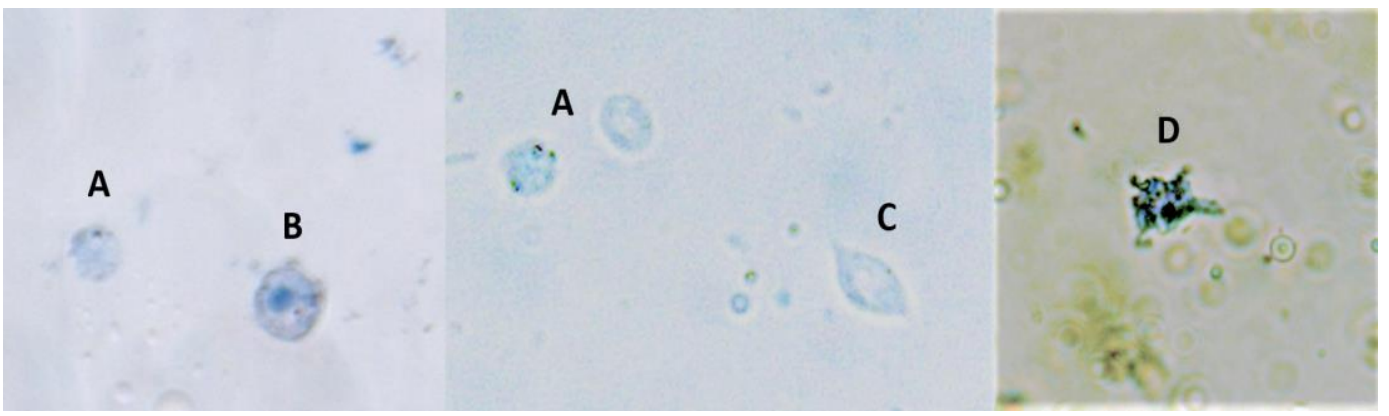

Fig. 2: Hemolymph cells observed after nanoparticle exposure. (A) normal plasmatocyte, (B) apoptotic plasmatocyte, (C) normal lamellocyte, (D) apoptotic lamellocyte (40x/0.75)

\section{Comet Assay}

The comet assay was used to observe potential DNA damage in the hemocytes of larvae exposed to Ch$\mathrm{Fe}_{3} \mathrm{O}_{4} \mathrm{NPs}$ DNA damage was detected by the presence of a comet tail in the cell nucleus. Comets without DNA damage and comets with a high level of DNA damage were identified (Fig. 3).

DNA damage in the hemocytes produced by exposure to each treatment was estimated based on the DNA percentage (DNA \%) in the comet tail and comet tail length. A direct association between $\mathrm{Ch}-\mathrm{Fe}_{3} \mathrm{O}_{4} \mathrm{NPs}$ concentration and DNA damage was observed. The level of DNA damage produced by each treatment was estimated based on the DNA percentage in the comet tail (Fig. 4A) and comet tail length ( $\mu \mathrm{m})$ (Fig. 4B). The highest level of DNA damage was observed in the larvae exposed to $1000 \mathrm{ppm}$, followed by the larvae exposed to $500 \mathrm{ppm}$ and the controlled larvae. However, non-statistical differences were observed between the larvae exposed to 500 and $1000 \mathrm{ppm}(\mathrm{p} \geq$ 0.05). Therefore, both $\mathrm{Ch}-\mathrm{Fe}_{3} \mathrm{O}_{4} \mathrm{NPs}$ concentrations were able to produce DNA damage, which contrasts with the control test.

\section{Lifespan}

The mean and maximum lifespans were estimated for flies exposed to $\mathrm{Ch}-\mathrm{Fe}_{3} \mathrm{O}_{4} \mathrm{NPs}$ (500 and $1000 \mathrm{ppm}$ ) and for non-exposed flies (control). The total lifespan was 67 days for non-exposed flies and 51 and 41 days for flies 
exposed to 500 and 1000 ppm, respectively. The maximum lifespan for non-exposed flies was 59 days; lifespan reduction of $26 \%$ (44 days) and 36\% (39 days) was observed for flies exposed to 500 and $1000 \mathrm{ppm}$, respectively (Fig. 5). Also a reduction of mean lifespan was observed in flies exposed to 500 and 1000 ppm, 18 and 23 days respectively; mean lifespan of non-exposed flies was 31 days. Statistical analysis did not show significant differences $(p$-value $=0.98)$ between the flies exposed to 500 and $1000 \mathrm{ppm}$.
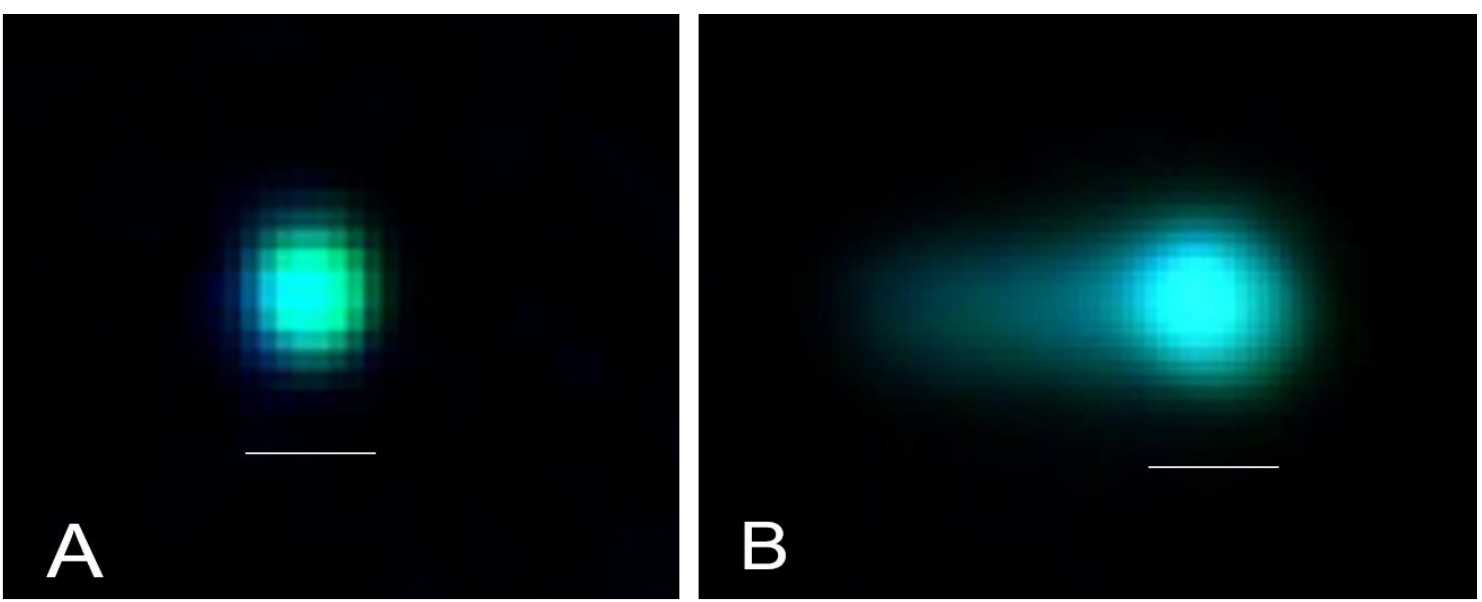

Fig. 3: Nucleus observed in the comet assay. (A) Hemocyte without comet tail, (B) hemocyte with comet tail and DNA damage. 400X $(\mathrm{Bar}=25 \mu \mathrm{m})$

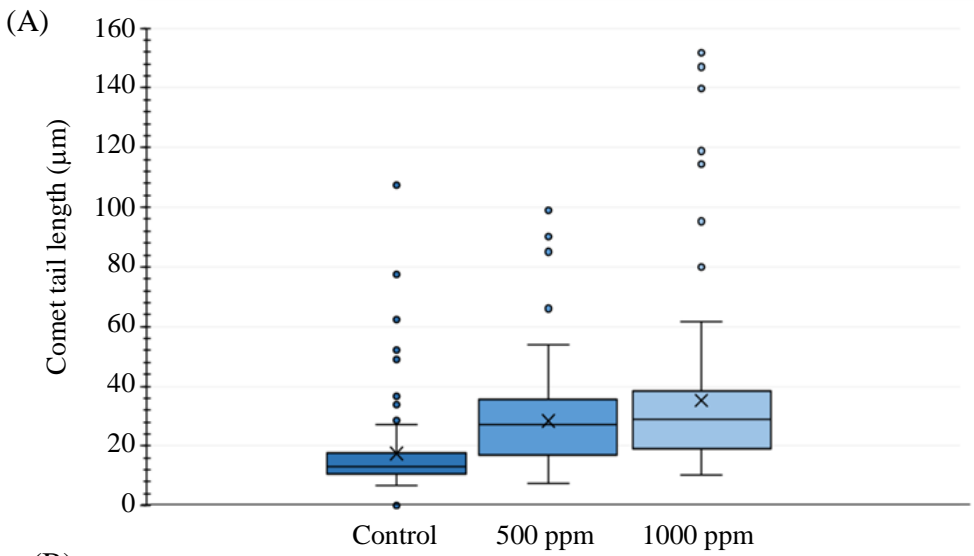

(B)

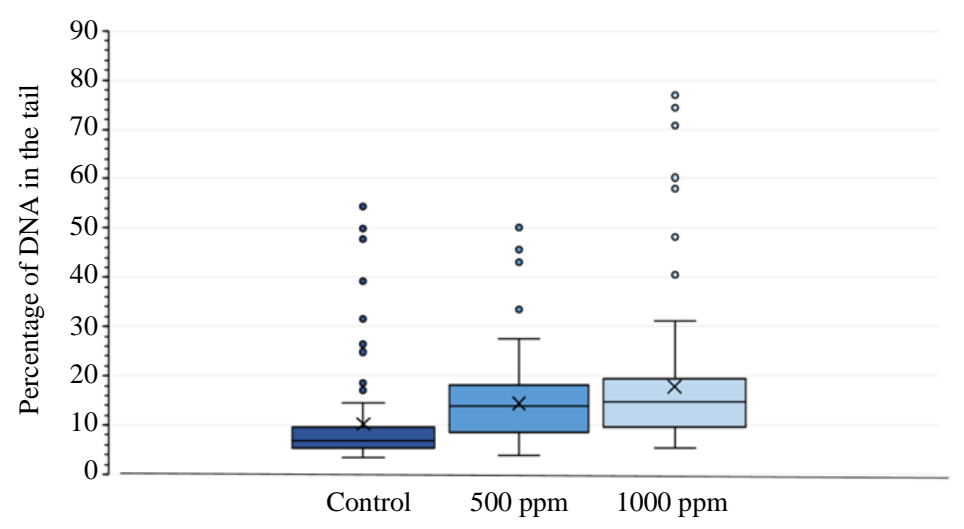

Fig. 4: DNA damage observed by the comet test assay. Two parameters were used to estimate DNA damage: (A) \% DNA in the comet tail and (B) comet tail length $(\mu \mathrm{m})$ 


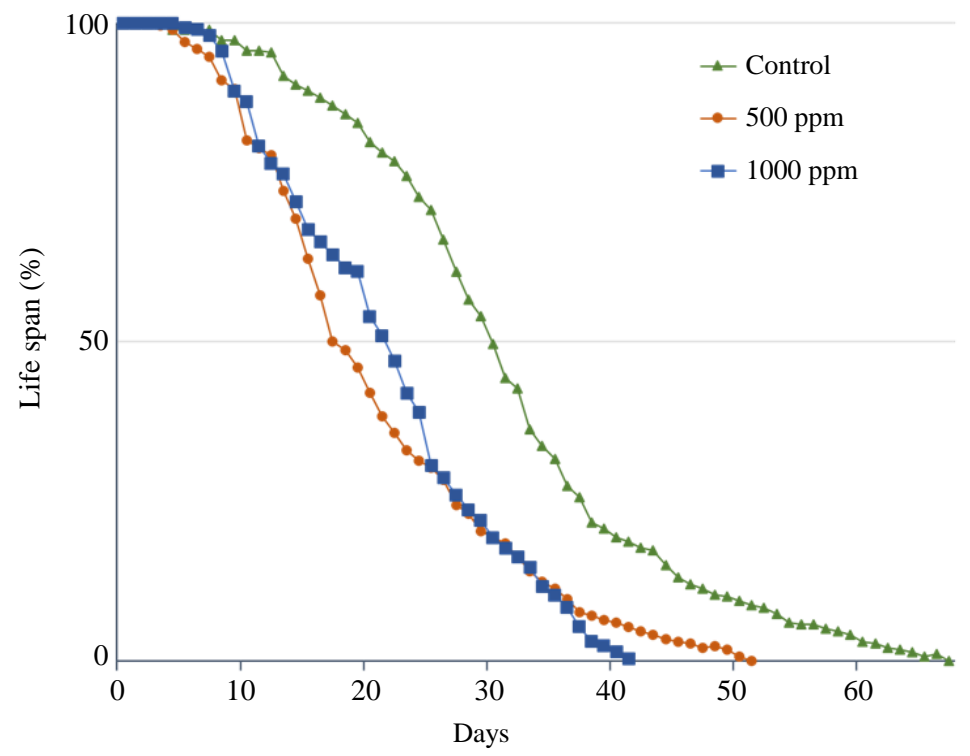

Fig. 5: Lifespan curves. Exposure to 500 and 1000 ppm of $\mathrm{Ch}-\mathrm{Fe}_{3} \mathrm{O}_{4} \mathrm{NPs}$ and the control without NPs

\section{Survival after Exposure to $\mathrm{Ch}-\mathrm{Fe}_{3} \mathrm{O}_{4} \mathrm{NPS}$}

The survival of larvae after exposure to $\mathrm{Ch}$ $\mathrm{Fe}_{3} \mathrm{O}_{4} \mathrm{NPs}$ was estimated. Survival was defined as the capacity of larvae to continue with metamorphosis up to the adult stage.

The parameter used to estimate larval survival was the percentage of flies hatched after exposure. The percentage of survival in non-exposed flies was $84 \%$ $($ mean $=84.6)$; this decreased to $61 \%($ mean $=61.0)$ in larvae exposed to $500 \mathrm{ppm}$ and to $51 \%($ mean $=51.3)$ in larvae exposed to $1000 \mathrm{ppm}$. Some differences were observed when the control group was compared to the 500 and $1000 \mathrm{ppm}$ exposure groups, but significant differences were also observed between the 500 and $1000 \mathrm{ppm}$ groups ( $\mathrm{p}$-value $=0.047$ ). Low survival is directly associated with the concentration of $\mathrm{Ch}$ $\mathrm{Fe}_{3} \mathrm{O}_{4} \mathrm{NPs}$; therefore, exposure to a highly concentrated dose of $\mathrm{Ch}-\mathrm{Fe}_{3} \mathrm{O}_{4} \mathrm{NPs}$ leads to high larva mortality.

\section{Discussion}

In this study, larvaes of D. melanogaster exposed to $\mathrm{Ch}-\mathrm{Fe}_{3} \mathrm{O}_{4} \mathrm{NPs}$ for $24 \mathrm{~h}$ presented changes in the cell density hemolymph composition: Increase in the number of plasmatocytes, emergence of lamellocytes and the presence of apoptotic plasmatocytes. Additionally, DNA damage in hemocytes and high mortality of larvae were observed.

The increase of plasmatocyte density and the emergence of lamellocytes were observed in larvae exposed to $500 \mathrm{ppm}$ and $1000 \mathrm{ppm}$ of $\mathrm{Ch}-\mathrm{Fe}_{3} \mathrm{O}_{4} \mathrm{NPs}$. However, the effect of $1000 \mathrm{ppm}$ concentration was toxic, while that of $500 \mathrm{ppm}$ was less harmful for the hemolymph cells. This observation can be explained by the presence of hemocytes, both those circulating (in the hemolymph) and sessile hemocytes (in the body wall), which have different functions during the immune response. Circulating plasmatocytes in the larvae arise from prohemocytes (embryonic macrophages); this differentiation occurs during normal larval development in Drosophila (Honti et al., 2010). However, when an event like the detection of pathogens, parasites, or foreign particles occurs, the cellular immune response is activated (Zettervall et al., 2004) and the sessile hemocytes detach from the epithelium and enter the circulating hemolymph, triggering the differentiation of plasmatocytes or lamellocytes and increasing the number of circulating hemocytes (plasmatocytes and lamellocytes). The emergence of lamellocytes could be explained by both prohemocytes and plasmatocyte differentiation, but plasmatocyte differentiation to create lamellocytes is triggered by immune induction (Honti et al., 2014; 2010; Stofanko et al., 2010). Therefore, both the increase in the number of circulating plasmatocytes and the emergence of lamellocytes could be a signals of immune response in front of toxic effect of the nanoparticles.

Larvae exposed to $1000 \mathrm{ppm}$ of $\mathrm{Ch}-\mathrm{Fe}_{3} \mathrm{O}_{4} \mathrm{NPs}$ showed the highest number of emergent lamellocytes (163 cells), apoptotic hemocytes (40 cells) and DNA damage. This suggests that high concentrations of nanoparticles could produce toxic effects in hemocytes. This dose-concentration effect of $\mathrm{Ch}-\mathrm{Fe}_{3} \mathrm{O}_{4} \mathrm{NPs}$ is supported by the statistical analysis that shows no difference between the $500 \mathrm{ppm}$ treatment and the control but significant difference between the $1000 \mathrm{ppm}$ treatment and the control. 
The presence of apoptotic cells is an indication of hemocyte damage and hemocyte death due to cell membrane damage. In this study, a high number of apoptotic cells were observed in larvae exposed to 1000 ppm of $\mathrm{Ch}-\mathrm{Fe}_{3} \mathrm{O}_{4} \mathrm{NPs}$, determined through the increase of blue-stained hemocytes in these larvae. Apoptosis plays a key role by eliminating cells subjected to various stress factors, (Gervais et al., 2015) in this case by toxic effect of nanoparticles.

In addition, $\mathrm{Ch}-\mathrm{Fe}_{3} \mathrm{O}_{4} \mathrm{NPs}$ ' toxic effect on DNA was demonstrated through the comet assay, the level of DNA damage can be determined by the DNA percentage in the comet tail and comet tail length. Comet assay provides a precise way to detect the effects of $\mathrm{Ch}-\mathrm{Fe}_{3} \mathrm{O}_{4} \mathrm{NPs}$ by means of measuring DNA strand breaks (Augustyniak et al., 2016; Collins, 2004); this allows for the identification of nanoparticles' possible mode of action at the molecular level. In this study, exposure to $1000 \mathrm{ppm}$ of Ch$\mathrm{Fe}_{3} \mathrm{O}_{4} \mathrm{NPs}$ produced the highest percentage of DNA in the comet and the longest comet tail.

In Drosophila, lifespan can be determined by genetic factors (Kimber and Chippindale, 2013; Zhou et al., 2018) but also by dietary nutrients (Hoedjes et al., 2017). Our results demonstrate that oral exposure to $\mathrm{Ch}$ $\mathrm{Fe}_{3} \mathrm{O}_{4} \mathrm{NPs}$ shortened mean and maximum lifespan, reduced larval survival, produce DNA damage and increased hemocytes number. Similar results have been reported in Drosophila after exposure to silver nanoparticles and cerium (a rare element that can produce oxidative damage); these events have been attributed to oxidative stress processes (Ahamed et al., 2010; Huang et al., 2010). Conversely, a diet that includes antioxidants has been found to extend lifespan and reduce signs of aging in Drosophila (Peng et al., 2012; Wang et al., 2015; Zhou et al., 2018). In previous studies, toxic effects of metal nanoparticles alters the lifespan of some insects (Jiang et al., 2015; Mehta et al., 2009; Small et al., 2016), for example in Blatella germanica, gold nanoparticles produces a sublethal effect on larval viability and lifespan reduction.

Ch- $\mathrm{Fe}_{3} \mathrm{O}_{4} \mathrm{NPs}$ ' toxic effect at 1000 ppm was demonstrated in this study, dose concentration was an important factors that influence the level of toxicity in hemocytes, larvaes and adults of D. melanogaster.

\section{Conclusion}

The toxic effect of $\mathrm{Ch}-\mathrm{Fe}_{3} \mathrm{O}_{4} \mathrm{NPs}$ at 1000 ppm was observed in the hemolymph of Drosophila larvae exposure to $\mathrm{Ch}-\mathrm{Fe}_{3} \mathrm{O}_{4} \mathrm{NPs}$. Were detected increase of hemocyte density, emergence of lamellocytes, presence of apoptotic hemocytes, DNA damage. Additionally, was observed shortening of lifespan and decreased larval survival associated with the toxic effect of doseconcentration of $\mathrm{Ch}-\mathrm{Fe}_{3} \mathrm{O}_{4} \mathrm{NPs}$. The nanoparticles' toxic effect at 500 ppm could have toxicity risks, but these have not been detected at all levels of NPs tested concentrations. These results are important for taking advantages of the $\mathrm{Ch}-\mathrm{Fe}_{3} \mathrm{O}_{4} \mathrm{NPs}$ characteristics and for planning the proper use in human activities.

\section{Acknowledgement}

To Karla Vizuete for preparing the samples for XRD analysis.

\section{Funding information}

This research was funded by the Pontificia Universidad Católica del Ecuador, project K13073 www.puce.edu.ec and by The World Academy of Sciences_grant RGA No. 13-216 RG/BIO/LA_I-UNESCO FR: 3240277722 https://twas.org/.

\section{Author's Contributions}

Doris Vela: Conceived and designed the experiments; performed the experiments; analyzed and interpreted the data; wrote the paper.

Jonathan Rondal: Performed the experiments.

Sofía Cárdenas: Performed the experiments.

Jose Gutiérrez-Coronado: Analyzed and interpreted the data.

Eliza Jara: Conceived and designed the experiments with nanoparticles; wrote the paper.

Alexis Debut: Analyzed and interpreted the data.

Fernanda Pilaquinga: Analyzed and interpreted the data; wrote the paper.

\section{Ethics}

This article is original and contains unpublished material. The corresponding author confirms that all of the other authors have read and approved the manuscript and no ethical issues involved.

\section{References}

Ahamed, M., Posgai, R., Gorey, T. J., Nielsen, M., Hussain, S. M., \& Rowe, J. J. (2010). Silver nanoparticles induced heat shock protein 70, oxidative stress and apoptosis in Drosophila melanogaster. Toxicology and applied pharmacology, 242(3), 263-269.

Alaraby, M., Annangi, B., Hernández, A., Creus, A., \& Marcos, R. (2015). A comprehensive study of the harmful effects of $\mathrm{ZnO}$ nanoparticles using Drosophila melanogaster as an in vivo model. Journal of Hazardous Materials, 296, 166-174.

Augustyniak, M., Gladysz, M., \& Dziewięcka, M. (2016). The Comet assay in insects-Status, prospects and benefits for science. Mutation Research/Reviews in Mutation Research, 767, 67-76. 
Brugnerotto, J., Lizardi, J., Goycoolea, F. M., ArgüellesMonal, W., Desbrieres, J., \& Rinaudo, M. (2001). An infrared investigation in relation with chitin and chitosan characterization. Polymer, 42(8), 3569-3580.

Canesi, L., Ciacci, C., Bergami, E., Monopoli, M. P., Dawson, K. A., Papa, S., ... \& Corsi, I. (2015). Evidence for immunomodulation and apoptotic processes induced by cationic polystyrene nanoparticles in the hemocytes of the marine bivalve Mytilus. Marine environmental research, 111, 34-40.

Carmona, E. R., Escobar, B., Vales, G., \& Marcos, R. (2015a). Genotoxic testing of titanium dioxide anatase nanoparticles using the wing-spot test and the comet assay in Drosophila. Mutation Research/Genetic Toxicology and Environmental Mutagenesis, 778, 12-21.

Carmona, E. R., Inostroza-Blancheteau, C., Obando, V., Rubio, L., \& Marcos, R. (2015b). Genotoxicity of copper oxide nanoparticles in Drosophila melanogaster. Mutation Research/Genetic Toxicology and Environmental Mutagenesis, 791, 1-11.

Cherry, S., \& Silverman, N. (2006). Host-pathogen interactions in drosophila: new tricks from an old friend. Nature immunology, 7(9), 911-917.

Chifiriuc, M. C., Ratiu, A. C., Popa, M., \& Ecovoiu, A. A. (2016). Drosophotoxicology: an emerging research area for assessing nanoparticles interaction with living organisms. International journal of molecular sciences, 17(2), 36.

Collins, A. R. (2004). The comet assay for DNA damage and repair. Molecular biotechnology, 26(3), 249.

Elsabahy, M., \& Wooley, K. L. (2015). Data mining as a guide for the construction of cross-linked nanoparticles with low immunotoxicity via control of polymer chemistry and supramolecular assembly. Accounts of chemical research, 48(6), 1620-1630.

Fauvarque, M. O., \& Williams, M. J. (2011). Drosophila cellular immunity: a story of migration and adhesion. Journal of cell science, 124(9), 1373-1382.

Gajski, G., Žegura, B., Ladeira, C., Pourrut, B., Del Bo, C., Novak, M., ... \& Dusinska, M. (2019). The comet assay in animal models: From bugs to whales-(Part 1 Invertebrates). Mutation Research/Reviews in Mutation Research, 779, 82-113.

Galenza, A., \& Foley, E. (2019). Immunometabolism: insights from the Drosophila model. Developmental \& Comparative Immunology, 94, 22-34.

Gervais, O., Renault, T., \& Arzul, I. (2015). Induction of apoptosis by UV in the flat oyster, Ostrea edulis. Fish \& shellfish immunology, 46(2), 232-242.

Ghazanfari, M. R., Kashefi, M., Shams, S. F., \& Jaafari, M. R. (2016). Perspective of Fe3O4 nanoparticles role in biomedical applications. Biochemistry research international, 2016.
Gillespie, J. P., Kanost, M. R., \& Trenczek, T. (1997). Biological mediators of insect immunity. Annual review of entomology, 42(1), 611-643.

Gregorio-Jauregui, K. M., Pineda, M., Rivera-Salinas, J. E., Hurtado, G., Saade, H., Martinez, J. L., ... \& López, R. G. (2012). One-step method for preparation of magnetic nanoparticles coated with chitosan. Journal of Nanomaterials, 2012.

Hedayatnasab, Z., Abnisa, F., \& Daud, W. W. (2018, March). Investigation properties of superparamagnetic nanoparticles and magnetic fielddependent hyperthermia therapy. In IOP Conference Series: Materials Science and Engineering (Vol. 334, No. 1, pp. 012042-012048).

Hoedjes, K. M., Rodrigues, M. A., \& Flatt, T. (2017). Amino acid modulation of lifespan and reproduction in Drosophila. Current opinion in insect science, 23, 118-122.

Honti, V., Csordás, G., Kurucz, É., \& Andó, I. (2014). The cell-mediated immunity of Drosophila melanogaster: hemocyte lineages, immune compartments, microanatomy and regulation. Developmental \& Comparative Immunology, 42, 47-56.

Honti, V., Csordás, G., Márkus, R., Kurucz, É., Jankovics, F., \& Andó, I. (2010). Cell lineage tracing reveals the plasticity of the hemocyte lineages and of the hematopoietic compartments in Drosophila melanogaster. Molecular immunology, 47(11-12), 1997-2004.

Huang, S. F., Li, Z. Y., Wang, X. Q., Wang, Q. X., \& Hu, F. F. (2010). Cerium caused life span shortening and oxidative stress resistance in Drosophila melanogaster. Ecotoxicology and environmental safety, 73(1), 89-93.

Iacovita, C., Stiufiuc, R., Radu, T., Florea, A., Stiufiuc, G., Dutu, A., ... \& Lucaciu, C. M. (2015). Polyethylene glycol-mediated synthesis of cubic iron oxide nanoparticles with high heating power. Nanoscale research letters, 10(1), 1-16.

Irving, P., Ubeda, J. M., Doucet, D., Troxler, L., Lagueux, M., Zachary, D., ... \& Meister, M. (2005). New insights into Drosophila larval haemocyte functions through genome-wide analysis. Cellular microbiology, 7(3), 335-350.

Jiang, S., Teng, C. P., Puah, W. C., Wasser, M., Win, K. Y., \& Han, M. Y. (2015). Oral administration and selective uptake of polymeric nanoparticles in Drosophila larvae as an in vivo model. ACS Biomaterials Science \& Engineering, 1(11), 1077-1084.

Kimber, C. M., \& Chippindale, A. K. (2013). Mutation, condition and the maintenance of extended lifespan in Drosophila. Current Biology, 23(22), 2283-2287.

Kroon, R. E. (2013). Nanoscience and the Scherrer equation versus the'Scherrer-Gottingen equation'. South African Journal of Science, 109(5-6), 01-02. 
Kumar, B., Smita, K., Cumbal, L., Debut, A., Galeas, S., \& Guerrero, V. H. (2016). Phytosynthesis and photocatalytic activity of magnetite (Fe3O4) nanoparticles using the Andean blackberry leaf. Materials Chemistry and Physics, 179, 310-315.

Lackie, A. M. (1988). Haemocyte behaviour. In Advances in Insect Physiology (Vol. 21, pp. 85178). Academic Press.

Lemaitre, B., \& Hoffmann, J. (2007). The host defense of Drosophila melanogaster. Annu. Rev. Immunol., 25, 697-743.

López, R. G., Pineda, M. G., Hurtado, G., León, R. D. D., Fernández, S., Saade, H., \& Bueno, D. (2013). Chitosan-coated magnetic nanoparticles prepared in one step by reverse microemulsion precipitation. International journal of molecular sciences, 14(10), 19636-19650.

Ma, P., Luo, Q., Chen, J., Gan, Y., Du, J., Ding, S., ... \& Yang, X. (2012). Intraperitoneal injection of magnetic Fe3O4-nanoparticle induces hepatic and renal tissue injury via oxidative stress in mice. International journal of nanomedicine, 7, 4809.

Markides, H., Rotherham, M., \& El Haj, A. J. (2012). Biocompatibility and toxicity of magnetic nanoparticles in regenerative medicine. Journal of Nanomaterials, 2012.

Massie, H. R., Aiello, V. R., \& Williams, T. R. (1985). Iron accumulation during development and ageing of Drosophila. Mechanisms of ageing and development, 29(2), 215-220.

Mehta, A., Deshpande, A., Bettedi, L., \& Missirlis, F. (2009). Ferritin accumulation under iron scarcity in Drosophila iron cells. Biochimie, 91(10), 1331-1334.

Mojica Pisciotti, M. L., Lima Jr, E., Vasquez Mansilla, M., Tognoli, V. E., Troiani, H. E., Pasa, A. A., ... \& Goya, G. F. (2014). In vitro and in vivo experiments with iron oxide nanoparticles functionalized with DEXTRAN or polyethylene glycol for medical applications: magnetic targeting. Journal of Biomedical Materials Research Part B: Applied Biomaterials, 102(4), 860-868.

Ong, C., Yung, L. Y. L., Cai, Y., Bay, B. H., \& Baeg, G. H. (2015). Drosophila melanogaster as a model organism to study nanotoxicity. Nanotoxicology, 9(3), 396-403.

Palanker-Musselman, L. (2013). Drosophila hemolymph collection procedure. [Video file]. Youtube. https://www.youtube.com/watch?v=im78OIBKIPA

Peng, C., Zuo, Y., Kwan, K. M., Liang, Y., Ma, K. Y., Chan, H. Y. E., ... \& Chen, Z. Y. (2012). Blueberry extract prolongs lifespan of Drosophila melanogaster. Experimental gerontology, 47(2), 170-178.

Ramesh, S., Grijalva, M., Debut, A., Beatriz, G., Albericio, F., \& Cumbal, L. H. (2016). Peptides conjugated to silver nanoparticles in biomedicine-a "value-added" phenomenon. Biomaterials science, 4(12), 1713-1725.
Shukla, S., Jadaun, A., Arora, V., Sinha, R. K., Biyani, N., \& Jain, V. K. (2015). In vitro toxicity assessment of chitosan oligosaccharide coated iron oxide nanoparticles. Toxicology reports, 2, 27-39.

Small, T., Ochoa-Zapater, M. A., Gallello, G., Ribera, A., Romero, F. M., \& Garcerá, M. D. (2016). Goldnanoparticles ingestion disrupts reproduction and development in the German cockroach. Science of The Total Environment, 565, 882-888.

Söderhäll, K., \& Cerenius, L. (1998). Role of the prophenoloxidase-activating system in invertebrate immunity. Current opinion in immunology, 10(1), 23-28.

Stofanko, M., Kwon, S. Y., \& Badenhorst, P. (2010). Lineage tracing of lamellocytes demonstrates Drosophila macrophage plasticity. PloS one, 5(11), e14051.

Sun, L., Chen, Y., Zhou, Y., Guo, D., Fan, Y., Guo, F., ... \& Chen, W. (2017). Preparation of 5-fluorouracilloaded chitosan nanoparticles and study of the sustained release in vitro and in vivo. asian journal of pharmaceutical sciences, 12(5), 418-423.

Wang, L., Li, Y. M., Lei, L., Liu, Y., Wang, X., Ma, K. Y., \& Chen, Z. Y. (2015). Cranberry anthocyanin extract prolongs lifespan of fruit flies. Experimental gerontology, 69, 189-195.

Wilson-Sanders, S. E. (2011). Invertebrate models for biomedical research, testing and education. ILAR journal, 52(2), 126-152.

Zettervall, C. J. Anderl, I., Williams, M. J., Palmer, R., Kurucz, E. Ando, I., \& Hultmark, D. (2004). A directed screen for genes involved in Drosophila blood cell activation. Proceedings of the National Academy of Sciences, 101(39), 14192-14197.

Zhang, L., Wang, X., Miao, Y., Chen, Z., Cui, L., ... \& Guo, Y. (2016). Magnetic ferroferric oxide nanoparticles induce vascular endothelial cell dysfunction and inflammation by disturbing autophagy. Journal of hazardous materials, 304, 186-195.

Zhang, Z., Han, S., Wang, H., \& Wang, T. (2014). Lutein extends the lifespan of Drosophila melanogaster. Archives of Gerontology and Geriatrics, 58(1), 153-159.

Zhou, Y. Z., Xue, L. Y., Gao, L., Qin, X. M., \& Du, G. H. (2018). Ginger extract extends the lifespan of Drosophila melanogaster through antioxidation and ameliorating metabolic dysfunction. Journal of Functional Foods, 49, 295-305. 